\author{
Economics Working Paper Series
}

\author{
2018/007
}

\title{
Did the London Congestion Charge Reduce Pollution?
}

Colin P. Green, John. S. Heywood and Maria Navarro

The Department of Economics

Lancaster University Management School

Lancaster LA1 4YX

UK

(C) Authors

All rights reserved. Short sections of text, not to exceed two paragraphs, may be quoted without explicit permission, provided that full acknowledgement is given. 


\title{
Did the London Congestion Charge Reduce Pollution?
}

\author{
Colin P. Green ${ }^{1}$, John. S. Heywood ${ }^{2}$ and Maria Navarro ${ }^{3}$ \\ ${ }^{1}$ Norwegian University of Science and Technology \\ ${ }^{2}$ University of Wisconsin-Milwaukee \\ ${ }^{3}$ Lancaster University
}

\begin{abstract}
We examine the London congestion charge introduced in 2003 and demonstrate significant reductions in a number of pollutants relative to controls. We even find evidence of reductions per mile driven suggesting amelioration of a congestion externality. Yet, we find a robust countervailing increase in harmful $\mathrm{NO}_{2}$ likely reflecting the disproportionate share of diesel vehicles exempt from the congestion charge. This unintended consequence informs on-going concern about pollution from diesel based vehicles and provides a cautionary note regarding substitution effects implicit in congestion charging schemes.
\end{abstract}

KEYWORDS: Pollution; Traffic; Congestion Charging.

JEL Codes: I18, R48, H27

Corresponding Author: Colin Green, Economics Department, Norwegian University of Science and Technology, Dragvoll, N-7491, Trondheim, Norway; colin.green@ntnu.no The authors thanks seminar participants at the University of Wisconsin- Milwaukee and the University of Nebraska for helpful comments. 


\section{Introduction}

Starting in 2003 the City of London imposed a charge for driving during prime hours on the roads in its central district. Supporters championed this congestion charge as a tool to battle the incredibly slow speeds and gridlocked traffic of the UK capital. These same supporters saw a "secondary benefit" of reduced air pollution (Transport for London, 2004). Whether or not this secondary benefit came to fruition has taken on increasing importance as a British Parliament select committee recently declared London air pollution a "public health emergency" (Carrington, 2016) and argued for new charges within the congestion zone specifically designed to combat vehicle emissions. ${ }^{1}$ With as many as 50 thousand premature deaths in the UK due to air pollution and with automobile exhaust the single most rapidly rising source of deaths worldwide (Lim et al., 2012), the time is ripe for understanding the consequences of the original London congestion charge on air pollution.

This paper examines the introduction of the London Congestion Charge Zone (CCZ) in 2003 focusing on three objectives. The first objective tests whether or not the CCZ reduced harmful pollutants associated with motor vehicles. The second objective, largely unexplored, tests for substitution effects implicit in the details of the congestion charge. We argue that the nature of the charge may result in substitution toward diesel based vehicles and so increase $\mathrm{NO}_{2}$ even as the concentration of other pollutants fell. The final objective recognizes that while pollution itself may evidence an externality, it may be made worse by the congestion externality. Thus, we test the extent to which the congestion charge reduced some pollutants beyond the underlying reduction in traffic flows. Such reductions happen when pollution per mile driven falls because

\footnotetext{
${ }^{1}$ Slated to start in September 2020, the Ultra Low Emission Zone requires cars, motorcycles, vans, minibuses, buses, coaches and heavy goods vehicles to either meet far tighter exhaust emission standards or pay a daily charge to travel. The charge will apply inside the current Congestion Charging Zone (CCZ) and will be in addition to the existing congestion charge. (Transport for London, 2015).
} 
of alleviating the congestion externality and improving road speeds (Edlin and Karaca-Mandic, 2006).

Air pollution stands as a textbook example of a negative externality unlikely to be 'inherently' priced into individual decisions. While governmental action is not new (e.g. the UK Clean Air Act of 1956 as a response to the 'great smog of London' in 1952), attention has been renewed in major cities where air pollution largely due to exhaust frequently exceeds harmful levels. Indeed, London has remained in violation of governmental standards continuously since 2010 and lost a critical Supreme Court decision for its failure to meet standards in 2015 (Harvey, 2015). The idea that reducing congestion can improve air quality and improve health seems sensible and has received support. Currie and Walker (2011) show that increased speed and eliminating the traffic congestion associated with toll road booths contributes significantly to improved health among infants. Knittel et al. (2016) use shocks in traffic interacted with weather to show that reduced automobile congestion reduces ambient air pollution and lowers infant mortality in California.

While a range of potential policy interventions might be implemented to address the externality of pollution, the efficient pricing of auto exhaust remains difficult. The determination of proper Pigouvian taxes depends on understanding the associated damages (Vickery 1963). These vary by type and vintage of vehicle, the number of other drivers on the road at the same time, the concentration of drivers nearby and the number of other non-driving citizens in close proximity (Newberry 1990). This variation means that second best uniform taxes like the gasoline tax perform very poorly in eliminating the deadweight burden associated with auto exhaust (Knittel and Sander, 2013). This has led to what are seen as more targeted approaches with urban road and driving charges among the leading candidates. 
London, Stockholm, Singapore and Milan have each adopted congestion charging within the last 15 years. Over the same period New York City, Hong Kong, Manchester and Edinburgh have rejected explicit bids for such charging. Such rejections often reflect political resistance to a charge not explicitly designed to pay for infrastructure (Hårsman and Quigley 2010). The adopting cities vary in their emphasis on increasing traffic speeds (London) and on reducing pollution (Milan). They also differ in earmarking the revenue from the congestion charge. London earmarked mass transit improvements while Stockholm earmarked road construction. Yet, insofar as these charges successfully reduces traffic flows, the schemes have the potential to reduce motor vehicle pollution in settings where the density of living and foot traffic is high and so where the damage from pollution is likely to be substantial.

While some trips to the city center simply may not take place, congestion charging policies seem more likely to change the method of transit. Driving becomes more expensive and, at least in London, mass transit was improved, especially the bus service. In addition, certain forms of transit were exempt from the London congestion charge. These included bikes, motorcycles, taxis and mass transit. ${ }^{2}$ As might be anticipated, these exemptions meant that more travelers used buses and taxis in central London (Transport for London, 2005). In both cases, this causes a move away from predominantly petroleum based transportation (private vehicles), towards a diesel based transportation (black cabs and buses).

As diesel combustion produces markedly higher levels of $\mathrm{NO}_{2}$ emissions, this makes the overall result on pollution somewhat ambiguous but it certainly suggests that the mix of pollutants may change. The $\mathrm{NO}_{2}$ more associated with diesel could well rise even as other pollutants decline. Importantly, $\mathrm{NO}_{2}$ is linked to a range of particularly adverse health outcomes

\footnotetext{
${ }^{2}$ Road safety initiatives together with the exemption on bikes resulted in a huge increase in cyclists in London with controversy surrounding the increase in cyclist injuries and in their breathing of exhaust (Green et al, 2016).
} 
including severe lung and respiratory problems (see for instance Guerriero et al., 2016). Moreover, the scientific consensus increasingly regards the association between respiratory morbidity and $\mathrm{NO}_{2}$ to be causal and not just a function of other associated pollutants (Committee on the Medical Effects of Air Pollution, 2015). This linkage has been driving broad and mounting concerns regarding the negative effects of diesel based pollution in urban settings. Indeed, the UK Department of Energy and Climate Change concludes that fumes from diesel are significantly more harmful than those from petrol engines and the World Health Organization lists diesel but not petrol fumes as a Group 1 carcinogen (Vidal, 2013). Historically diesel engines also emitted higher levels of particulate matter than petrol engines. However, changes in modern diesel engines over the last two decades first closed, and then reversed, this gap. Recent diesel engines actually emit less particular matter (Platt et al., 2017).

We are not the first to ask the question of whether congestion charges reduce pollution. Tonne et al. (2008) examine the London congestion charge finding a modest reduction in pollution simply looking before and after without control jurisdictions. Yet, critically their projections assumed that the vehicle fleet remained constant which given the exemptions seems highly unlikely. Atkinson et al. (2009) use jurisdictions within London as controls finding mixed results depending on pollutant and methodology. Such evidence lacks suitable comparison groups and control variables and like early work on other consequences of the CCZ seem unlikely to be reliable (Green et al., 2016). Gibson and Carnovale (2015) examine the introduction, and temporary cessation, of the Milan congestion charge and demonstrate marked reductions in $\mathrm{CO}$ and measures of particulate matter. The fees in Stockholm reduced ambient air pollution by 5 to 10 percent and this reduction resulted in a significant decrease in acute asthma attacks among young children (Simeonova et al., 2017). The mixed results, locations and 
methods of these studies certainly leave room for a new examination of the London CCZ and its consequences on air pollution.

To summarize our findings, we demonstrate varied but substantial reductions in three traditional pollutants but a sharp increase in $\mathrm{NO}_{2}$ emissions. The reduction of the first three pollutants can credibly be linked to the reduction in petrol-based and overall motor-vehicular transportation. We argue the $\mathrm{NO}_{2}$ increase likely reflects the unintended incentives that the charging scheme provided to shift towards diesel based transportation. We also show that the reduced emissions in the three basic pollutants exceeds that expected from the reduction in traffic flows alone. As such, it provides evidence of these pollutants (but obviously not $\mathrm{NO}_{2}$ ) being reduced because of ameliorating a congestion externality. In the end, we further examine statistical inference by adjusting in various ways for the small number of treated jurisdictions. This reveals that the increase in $\mathrm{NO}_{2}$ stands as a far more robust result than the reduction in the traditional pollutants.

The remainder of the paper is structured as follows. The next section provides background information on the introduction of the CCZ. Section 3 sets out the data sources and empirical methodology. Section 4 provides the results, while section 5 concludes.

\section{Background on the Congestion Charge}

Central London has long been among the most congested of Western cities. Traffic speeds decreased and vehicle counts increased continuously over the second half of the $20^{\text {th }}$ century. Just prior to imposing the congestion charge, all-day average speeds averaged a low $8.6 \mathrm{mph}$ and more than 1/3 of all travel time was spent at a complete standstill (Transport for London, 2003). 
The London congestion charge was first imposed on the $17^{\text {th }}$ of February 2003. The initial charge was $£ 5$ for entering the congestion zone between 7 a.m. and $6: 30$ p.m. on weekdays. Despite subsequent increases in fees ( $£ 8$ in 2005, $£ 10$ in 2011 and $£ 11.50$ in 2014), and charging times (reduced to 6pm in February 2007), the charge still exists largely in its original form. Passes can be purchased on-line and enforcement relies on a series of video cameras at every entry point to the zone and on mobile units within the zone. A sophisticated license plate recognition system matches against daily purchases and violators are sent penalty notices for escalating fines that average 20 to 30 times the daily charge. The day pass allows travel in and around the congestion zone of Central London. This eight square mile zone includes tourist sites, the City (London's financial district), Parliament, major government offices and prime business locations (see Figure 1). This zone was extended in February $17^{\text {th }} 2007$ to take in areas immediately west of the initial congestion zone (the so-called 'Western Extension') but this extension was subsequently removed in December $24^{\text {th }} 2010 .^{3}$ As discussed later, this timing ultimately influences our policy window.

\section{$<$ INSERT FIGURE $1>$}

The charge applies to private and commercial vehicles entering the congestion zone during the charging hours, but motorcycles, bicycles, buses and taxis are exempt. There are exemptions for vehicles belonging to those who live within the zone but keep their vehicles off the street during the charging hours. When these residents do travel during the charging hours, they pay a highly discounted charge of 10 percent of the full charge.

\footnotetext{
${ }^{3}$ It is also worth noting that in February 2008 the Low Emission Zone (LEZ) policy was introduced which charged certain high emission vehicles for driving in the Greater London area.
} 
Revenue raised from the charge program is earmarked primarily for mass transit improvements, along with smaller expenditures on road safety and bike/walking initiatives. ${ }^{4} \mathrm{~A}$ key part of the mass transit initiative was an expansion of the bus transit network within the zone and across London. Leape (2006) reports initial changes in traffic flows after the introduction of the congestion charge. Notably, while overall traffic volume decreased, bus travel flows increased by $22 \%$ and Taxi flows increased by $21 \%$. As emphasized, this raises potentially unintended consequences as, in London, these two types of vehicle are exclusively diesel powered.

\section{Data and Methodology}

The data used in this paper come from several administrative sources. We draw pollution data for both the CCZ and the control districts from the fixed location monitoring stations within the UK. We focus on a set of pollutants related to vehicular traffic for which we have consistent data across our period of interest: $\mathrm{CO}, \mathrm{NO}, \mathrm{PM} 10$ and $\mathrm{NO}_{2}$. We collect emission data from stations within the congestion zone area and from the other urban areas of Britain outside of London. ${ }^{5}$ This reflects both the focus of our paper, but also a pragmatic choice due to data management issues. The concentrations of the specific pollutants are reported hourly from each station.

We restrict our data to the period from 2000 to 2007 . First, pollution data before 2000 is less reliable and there are fewer emission reporting stations. Second, we attempt to achieve consistency by roughly balancing the time before and after the introduction of the CCZ. Third,

\footnotetext{
${ }^{4}$ Note that the well-known London Bike rental programme, colloquially known as Boris Bikes, did not start until 2010 and is separate from the Congestion Charge initiative.

${ }^{5}$ We chose for our control group the largest UK cities that had pollution monitoring stations in a fixed location over the time period being examined. The control group consists of Aberdeen, Belfast, Birmingham, Brighton, Bristol, Cardiff, Glasgow, Hull, Leeds, Leicester, Manchester, Newcastle, Nottingham, Plymouth, Portsmouth, Sheffield, Southampton, Stoke, Swansea and Wolverhampton.
} 
we stop at 2007 as the Low Emission Zone (LEZ) introduced in early 2008 seems a potentially important confounding factor. ${ }^{6}$ This also means that we are examining the effect of the CCZ before the also potentially confounding introduction of the western extension. While clearly of interest, the pollution effects of this extension cannot easily be disentangled from any effects of the LEZ.

In addition to this data we utilize weather data drawn from the Met Office-MIDAS Land Surface Station Data Source. We match weather and emissions stations geographically and use daily weather information. In a final set of estimates, we match our emissions data to traffic flows data available from the Traffic Count Data Source collected by the Department of Transport.

The traffic flows data has two complications. First, it is annual providing fewer observations and less precision. Second, the disaggregation by vehicle type is limited by the underlying mechanics of the surveying technology. As a consequence, we cannot distinguish between private cars and taxis in the flow data. We discuss our approaches to using this data in more detail later when discussing our pollution rate estimates.

Our basic approach is to estimate variants on the following:

$$
P_{i t}=\phi+\delta C C Z_{i}+\alpha \text { Policy }_{t}+\beta\left(C C Z_{i} * \text { Policy }_{t}\right)+\gamma X_{i t}+\tau T_{t}+\varepsilon_{i t}
$$

The underlying observation is a reporting station $i$ at time t. The coefficient $\beta$ provides a difference-in-difference estimate of the effect of the introduction of the CCZ on pollutant $P$. CCZ indicates pollutant emissions occurring in the congestion zone. We observe two stations within

\footnotetext{
${ }^{6}$ This was a more modest version of the Ultra Low Emission Zone described in the introduction. It did charge certain vehicles if they had extremely high emissions.
} 
the zone (Bloomsbury and Westminster) and our main approach is to use both. ${ }^{7}$ In robustness checks we estimate (1) using each station in turn. Policy is an indicator variable for an observation from the $17^{\text {th }}$ of February 2003 onwards. $X$ is a vector of controls, while T is initially a linear time trend. Our dependent variable is an hourly pollution reading with the core estimates limited to the hours of the congestion charge.

We estimate (1) separately for each of the 4 pollutants. As emphasized, the substitution to diesel transport suggests that $\beta$ may be differently signed according to pollutant type. Our basic estimates cluster standard errors at the level of the local jurisdiction. We subsequently examine the robustness of our inference to small cluster concerns.

As an initial descriptive step Figure 2 presents information on average pollutant levels before and after the introduction of the $\mathrm{CCZ}$ for the treatment and control stations. To aid visualization, we convert the three main pollutants to their Z-scores and average. The Figure demonstrates that the pollutant levels for our comparison group decline over the sample period and at a similar gradient to the CCZ for the pre-policy period. The introduction of the congestion charge is associated with a substantial drop in the 3 pollutants in the $\mathrm{CCZ}$ and perhaps with a flattening as well that differs from the control jurisdictions.

\section{$<$ INSERT FIGURE 2 >}

Figure 3 plots similar data for $\mathrm{NO}_{2}$. Here the decline in the pre-treatment period in $\mathrm{NO}_{2}$ levels within the $\mathrm{CCZ}$ is pronounced. Yet, the arrival of the policy within the $\mathrm{CCZ}$ is associated with a dramatic increase in $\mathrm{NO}_{2}$ and, again, a flatter trend. This stark change is not apparent for

\footnotetext{
${ }^{7}$ We cannot identify PM10 within the charged time for the Winchester station as it provides only daily measures for PM10. As a result our main estimates for PM10 are for only the Bloomsbury station. In unreported results, we estimate daily observation models of PM10 using both Bloomsbury and Westminster together. These are available upon request but the resultant policy estimates remain essentially unchanged from.
} 
the control group. The clear differences in pre-trend slope between the two groups will require accounting for in the estimations in the results section that follows.

\section{< INSERT FIGURE 3 >}

These initial pictures of the data suggest that the congestion charge is associated with dramatic changes within the treatment area of London but has essentially no influence on pollution levels of the controls. In the face of a series of robustness checks and more sophisticated estimates, these initial patterns show differential persistence. Wild bootstrapping leaves evident both the increase $\mathrm{NO}_{2}$ and the decrease in the other three pollutants. Yet, in synthetic cohort and Conley-Taber estimates, the strong increase in $\mathrm{NO}_{2}$ persists but the decline in the other three pollutants becomes less evident. This puts even greater emphasis on our story of the unanticipated consequences associated with the shift toward diesel engines associated with the CCZ.

\section{Results}

Table 1 provides estimates of the impact of the introduction of the congestion charge on the four different pollutants. We report estimates for a narrow window of 2000-2005 and for a more complete window of 2000-2007. This provides a gauge of differences between short and medium term policy effects, and helps judge robustness to focusing on less 'balanced' pre and post-policy analysis. For illustrative purposes, we also demonstrate the narrower window estimates with and without controls for differential pre-trends between the control and treatment stations. All models include controls that capture daily, monitoring station level, weather variation. Weather 
conditions profoundly influence pollutant concentrations and the concern is that weather differences over time and between treatment and control may influence the results.

\section{$<$ INSERT TABLE 1>}

The first point to note is that generally the introduction of the CCZ appears to have led to a reduction in the levels of the first three pollutants, $\mathrm{CO}, \mathrm{PM}_{10}$ and NO. However, the effects of the $\mathrm{CCZ}$ on both $\mathrm{CO}$ and NO pollutant levels are sensitive to both time period and potential violations of the common trend assumption. ${ }^{8}$ The results for $\mathrm{NO}_{2}$ are starkly different. The key estimate of interest remains positive across all specifications. Here there exists some evidence of a diminution of effect in later years. Nonetheless, the effect magnitudes are large. In estimates that include CCZ specific trends, which appear important in this case, the effect size is a 7.7 (unit) increase in the long window ( 0.38 of the $\mathrm{CCZ}$ pre-change standard deviation and 0.14 of the $\mathrm{CCZ}$ mean) and a 14.7 (unit) increase in the short window (0.72 of the pre-change CCZ standard deviation and .026 of the CCZ mean). ${ }^{9}$ This provides initial evidence of marked substitution effects as a result of the congestion charge, insofar as traditional pollutants decrease while $\mathrm{NO}_{2}$, associated with diesel, increases dramatically.

\section{$<$ INSERT TABLE $2>$}

We recognize that there are differences in monitoring station locations, and types, which may influence measurement of pollution. One concern is that these variations may influence the key measurements in the treatment area and across our controls. Many of these critical aspects are time fixed in nature. A related concern is that there may have been compositional changes in

\footnotetext{
${ }^{8}$ However, if one averages the z-scores of the three pollutants as in Figure 2, the difference-in-difference for that average is routinely statistically significant.

${ }^{9}$ The descriptive statistics on the pollutants are presented in the appendix.
} 
the controls across the period, due to changes in monitoring stations, new stations becoming active etc. We investigate this by re-estimating our main models introducing monitoring station fixed effects. This allows us to both remove the effect of time invariant monitoring station specific factors, while also mitigating some of the concern regarding composition of the controls as the treatment effect is only identified relative to control stations observed before and after the CCZ introduction. These are reported in Table 2. In general, these closely follow the earlier results. In additional unreported results we re-estimated our main models specifically excluding stations with numerous missing observations or that were not present across the whole period. Again our main results were essentially unaffected by this.

Table 3 demonstrates analogous results but where we retain station fixed effects but instead the dependent variables are the natural logs of each pollutant. This robustness check is motivated by both a concern with potential outliers and by the possibility that the linear specification is inappropriate. It also has the advantage of aiding interpretation of treatment effect magnitudes. We again report estimates for a narrow window of 2000-2005 with and without controls for differential trends, and for a more complete window of 2000-2007. These results largely follow the patterns from Tables 1 and 2. The introduction of the CCZ lead to substantial reductions in CO, PM10 and NO. These range in both size of effect and robustness. CO effects are relatively small and appear to diminish in later periods insofar as the 2000-2007 effect size is smaller and no longer statistically significant at standard levels. Both NO and PM10 reductions are larger and appear to get larger over time. The pattern of increases in $\mathrm{NO}_{2}$ reported in Table 1 remain and are as large as .2 log points. The take home point from Table 3 is that the earlier results remain, and are not a function of using levels. In subsequent models we revert to pollutant levels, but stress that all results remain qualitatively similar with log pollutants. 


\section{$<$ INSERT TABLE $3>$}

In a further concern with robustness we recognize that identification of the key parameters come from a change in policy by a small number of groups (two reporting stations) in a relatively small number of overall groups. Clustering at the local authority level in this case can cause the reported standard errors to be misleadingly small. In response we implement the Wild bootstrap procedure from Cameron et al. (2008). This reduces the high type I error rates common in the presence of clustering on a small number of groups. The procedure replicates the within group correlation in errors when generating new estimates (Cameron and Miller 2015). Under the null hypothesis of no difference in difference effect, the Wild bootstrap p-values clustered at a local authority level with 10,000 replications are presented in Table 1, Table 2 and Table 3. In no case in Table 1 does the bootstrapping reverse the claims of statistical significance. It continues to appear that the congestion charge reduced the traditional pollutants but increase $\mathrm{NO}_{2}$. The vast majority of claims of statistical significance persist in Tables 2 and 3 and certainly the general pattern strongly persists.

\subsection{Rates of Pollution}

To this point we have demonstrated robust reductions for a base set of pollutants associated with petrol based vehicles, and a robust increase in emissions of $\mathrm{NO}_{2}$ closely linked to diesel based vehicles. The original hope for the $\mathrm{CCZ}$ was that it would improve speeds and reduce gridlock. Both Leape (2006) and Green et al. (2016) suggest that this happened. This, in turn, raises the possibility that changes in pollution might also reflect that a congestion externality was ameliorated. In the case of the traditional pollutants, if they were reduced simply in proportion 
to the miles driven, the pollution externality itself might be reduced but there would be no evidence of an improved congestion externality. The congestion externality would be improved if each trip driven by a charged vehicle into London was associated with less pollution. ${ }^{10}$ This would happen because less time was spent in slow or stalled traffic. We now turn to this question: did the introduction of the congestion charge influence pollution per mile for charged vehicles?

We examine this by combining our earlier pollution data with traffic flow data sourced from the Department of Transport. This data is only available at an annual level and as a result we aggregate our pollution data up to annual data. We compute the average pollution across the year with the charged time for each local jurisdiction. The dependent variable then becomes this average charge time emission in the year divided by the million of miles driven in the jurisdiction per year.

As mentioned, a further complication is that the surveying technology cannot distinguish between private cars and taxis, when ideally we would like to completely disentangle flows by charging status. We adopt two approaches to examining this issue. In the first we divide emissions by all mileage flows both charged and not charged. In the second we divide emissions by the closest categorization of charged mileage flows available. For our combined pollutants this is cars. Both approaches introduce measurement error but they should create a band of reasonable estimates. We estimate analogous models to (1) that include monitoring station fixed effects and where for brevity we report only estimates for 2000-2007 including differential trends. These results are included as Table 4 for the estimate that uses our proxy for charged miles.

\footnotetext{
10 This mirrors Edlin and Karaca-Mandic (2006) who argue that only a reduction in traffic accidents per mile driven is evidence of ameliorating a congestion externality.
} 


\section{$<$ INSERT TABLE $4>$}

Interpreting these results requires recognizing that a zero estimate would imply that the earlier estimates entirely reflect changes in traffic flows. In other words, the decline in pollution merely reflected a decline in miles driven. Yet, this is not the case. There is a marked reduction in the rate of emissions for $\mathrm{PM}_{10}$ and NO. These do not markedly vary when using the alternative flow of all miles driven rather than our proxy for charged miles. This result suggests that the introduction of the charge reduced pollution beyond what would have been expected from the reduction in traffic flows itself. Thus, part of the reduction in the traditional pollutants came from reduced congestion indicating that not only the pollution externality was improved but that a congestion externality was also improved. The reductions in the rates of PM10 and NO appear roughly of the same magnitude as in the estimates without rates but this is only an artifact resulting from dividing by millions of miles in the jurisdiction and that average number of miles is not far from a one million miles (see appendix). As the charged miles and the total miles are not dramatically different, the reductions in the rates for PM10 and NO are roughly similar when dividing by the later (available upon request).

The evidence on $\mathrm{NO}_{2}$ shows a very large increase in the rate of pollution. This increase of over 20 in the concentration per million miles falls when dividing by total miles rather than charged miles. The fall in charged miles is more marked and so the increase in $\mathrm{NO}_{2}$ looks somewhat more dramatic. Nonetheless, the increase when using total miles remains over 14 in the concentration and highly significant (also available upon request). This unique sensitivity of the $\mathrm{NO}_{2}$ to the choice of miles (charged vs. total) continues to argue that it is associated with uncharged vehicles. 
The vehicle flows that underlie these estimates are of interest in their own right. They allow us to expand on this point and show how the composition of vehicle miles driven changed as a result of the congestion charge. Table 5 estimates the difference in difference on the annual data for total miles driven and for miles driven by each type of vehicle that is given in our traffic flow data. The results show the decline in total miles driven. Yet, counteracting this general movement is an increase in uncharged miles by buses, motorcycles and bicycles. The results also show the decline in the charged miles by cars (including taxis) and heavy vehicles together with a modest uptick in charged miles by light vehicles. We use these estimates to make a back of the envelope calculation to suggest the increase in the miles driven by diesel powered vehicles.

\section{$<$ INSERT TABLE $5>$}

While it is easy to observe the miles driven by diesel buses and transport vehicles (light and heavy), it requires sensible assumptions to imagine what happens to diesel powered taxis. We know from our data that the average annual miles driven in the CCZ prior to the charge by cars and taxis together is 478.70 million miles. From Leape (2006) we know that prior to the charge 24.9 percent of all taxi and car miles in the CCZ were from taxis or 119.20 million miles. We also know from the estimates in Table 5, that the average increase in miles driven by uncharged vehicle categories is $8.5 \%$. If we assume that taxi miles increased by this same percent, the increase in diesel powered taxi miles is 10.13 . This can be added to the net increase in the other diesel powered vehicles (buses and transport vehicles) for a total increase of 11.17 million miles per year. Thus, increases in diesel miles driven stands a crucial indicator behind the substantial increase in $\mathrm{NO}_{2}$ generated by the congestion charge. 


\subsection{Additional Concern with Robustness and Inference}

We have presented a cautionary tale about the changing composition of pollution and isolated the increasing concentration of dangerous $\mathrm{NO}_{2}$ even in the face of fewer driven miles and lower concentrations of other pollutants. We argue that the rise in $\mathrm{NO}_{2}$ reflects the increase in miles driven toward more diesel powered miles disproportionately exempt from charging. We now turn to two further exercises design to test the sensitivity of this conclusion.

One feature of the data illustrated in Figs. 2 and 3 is the large differences in average pollution levels between the CCZ and the average of other UK cities. This reflects the unique position of central London in terms of activity and traffic density. This might cause concern regarding the suitability of our control group. To explore the suitability of our control we adopt the synthetic panel approach as set out by Abadie and Gardeazabal (2003). This involves optimally weighting the comparison group to match the pre-treatment pollution data for the CCZ. When examining $\mathrm{NO}_{2}$, the mean squared prediction error between the $\mathrm{CCZ}$ and the control was reduced from 359 over all of the control cities to only 12.2 with the optimal weighting of those cities. The procedure gave weight to two cities with Hull and Manchester receiving all of the weighting, 0.491 and 0.509 respectively. While this approach provides superior matching of preevent data, it greatly reduces the total number of observations with only a single control observation per period.

The matching and synthetic control approach is performed separately for the three traditional pollutants and for $\mathrm{NO}_{2 .}{ }^{11}$ The results are presented in Table 6. The first two columns examine the shorter time frame for the four pollutants. The difference-in-difference coefficients

\footnotetext{
${ }^{11}$ Manchester and Hull also played prominently in the synthetic cohorts for other three pollutants but each of these cohorts were based on a wider variety of jurisdictions - typically four or five. These breakdowns are available upon request.
} 
emerge with the expected negative coefficient for all three basic pollutants but they are never statistically different from zero. In contrast, the results for $\mathrm{NO}_{2}$ emerge as large, positive and highly significant. Indeed, the estimated increases in concentration for $\mathrm{NO}_{2}$ are actually larger than those not using the synthetic control and now exceed the pre-charge standard deviation (see the appendix). The final column explores the longer time frame. It shows a modest and statistically weak reduction in PM10, no influence on the other two basic pollutants but a continued very large and highly significant increase in $\mathrm{NO}_{2}$.

\section{<INSERT TABLE 6>}

In addition, we examine an alternative for establishing inference on the difference-indifference estimate. Here we follow the randomization inference procedure of Conley and Taber (2011) which is based on estimated coefficients (or where treatment point estimators can be used as test statistics). Using test statistic inversion, we construct confidence intervals in order to identify the key parameter when its identification arises from changes in policy by a small number of groups.

Table 7 presents the results for the aggregated basic pollutants with pollutant specific fixed effects, for the individual basic pollutants and for $\mathrm{NO}_{2}$. The results reflect individual tests for each of the two testing stations within the CCZ. The confidence band for the sum of the traditional pollutants leaves the direction of change, if any, in doubt. Zero is centrally located in each confidence band providing virtually no information.

The individual pollutants provide inconsistent and heterogeneous results. Three of the estimates for $\mathrm{CO}$ are uninformative while Westminster for the shorter time frame indicates a 
significant decline. The estimate for PM10 is significantly negative for Bloomsbury in the longer time frame. ${ }^{12}$ The estimate for $\mathrm{NO}$ is significantly negative for Bloomsbury in both time frames but never for Westminster. At best, there is weak support for a decline in the traditional pollutants. This broadly fits the synthetic cohort estimate by implying that inference varies with technique and is not robust for the traditional pollutants.

\section{$<$ INSERT TABLE 7>}

The $\mathrm{NO}_{2}$ results present a more consistent picture. All four estimates suggest that the levels of $\mathrm{NO}_{2}$ increased as a result of the congestion charge and three of the four estimates have confidence bands that rule out negative estimates indicating statistical significance. Again, as with the synthetic cohort estimate, the inference of $\mathrm{NO}_{2}$ proves more robust and emphasizes the importance of our cautionary tale about the hidden cost of exempting vehicles that are diesel powered.

\section{Conclusion}

Air pollution in central cities has been a source of increasing concern. As vehicle exhaust represents a huge share of urban pollution, congestion charging offers a method of reducing total travel miles, increasing travel speed and reducing pollution. This paper examines the effect of the London Congestion Charge introduced in 2003 on a range of emissions. We demonstrate significant reductions across a range of pollutants in comparison to comparison cities in the same period. Moreover, these reductions are substantially larger than what would be expected from

\footnotetext{
${ }^{12}$ Again, hourly PM10 measures are not available for Westminster but using this technique with analogous daily measures shows that zero is clearly within the confidence interval.
} 
the reduction in traffic flows by itself. Thus, the charging scheme not only internalized a pollution externality, but had additional socially beneficial effects through the reduction of the congestion externality by speeding up travel time and reducing pollution per mile.

At the same time we focus on one particular pollutant closely linked to diesel powered motor vehicles, $\mathrm{NO}_{2}$. Exempting buses and taxis meant that these diesel vehicles drove many more miles as a result of the congestion charge as commuters transferred out of personal cars into these forms of public transport. This reflected an explicit policy to expand public transport provision in the zone. As a consequence, the fuel mix of vehicles in the zone moved toward diesel to such an extent that diesel miles increased.

We demonstrate that the reduction in other pollutants has to be weighed against negative health effects associated with a marked increase in $\mathrm{NO}_{2}$ emissions. Our experimentation with alternative inference methods makes clear that the increase in $\mathrm{NO}_{2}$ emissions remains the most robust of the results we present. This provides a cautionary note regarding substitution effects implicit in congestion charging schemes. Reducing congestion and reducing the harms of air pollution may be related but are certainly not identical as our study shows. Indeed, the concern with diesel in Europe continues to grow with Dusseldorf and Stuttgart moving toward simply banning older diesel fueled vehicles. These and related moves now seem legally allowed by a recent German court ruling (Connolly, 2018). London continues to have exemptions to the congestion charge that we have argued may be harmful but at the same time it has begun to increasingly rely on alternative charges (such as the LEZ) to reduce pollution. The overall influence of these seemingly contradictory policies has yet to be observed. 


\section{References}

Alberto Abadie \& Javier Gardeazabal, 2003. "The Economic Costs of Conflict: A Case Study of the Basque Country," American Economic Review, 93:113-132.

Atkinson, Richard W., et al. 2009. "The impact of the congestion charging scheme on ambient air pollution concentrations in London." Atmospheric Environment 43: 5493-5500.

Cameron, A. Colin., Jonah B. Gelbach, Douglas L. Miller. 2008. “Bootstrapped-based Improvements for Inference with Clustered Errors," Review of Economics and Statistics 90: 414-427.

Cameron, A. Colin., and Douglas L. Miller, 2015. “A Practitioner's Guide to Cluster-Robust Inference" Journal of Human Resources, 50: 317-372.

Carrington, Damien. 2016. "MPs: UK Air Pollution is a 'Public Health Emergency'," The Guardian, April 27. https://www.theguardian.com/environment/2016/apr/27/uk-airpollution-public-health-emergency-crisis-diesel-cars

Committee on the Health Effects of Air Pollution. 2015. Statement on the Evidence for the Effects of Nitrogen Dioxide on Health, https://www.gov.uk/government/uploads/system/ uploads/attachment_data/file/411756/COMEAP_The_evidence_for_the_effects_of_nitrog en_dioxide.pdf

Conley, Timothy G., and Christopher R. Taber. 2011. "Inference with "difference in differences" with a small number of policy changes." The Review of Economics and Statistics 93: 113-125. 
Connolley, K. (2018). "German court rules cities can ban diesel cars to tackle pollution," The Guardian, February 27, https://www.theguardian.com/environment/2018/feb/27/germancourt-rules-cities-can-ban-diesel-cars-to-tackle-pollution

Currie, J., \& Walker, R. (2011). Traffic congestion and infant health: Evidence from E-Z Pass. American Economic Journal: Applied Economics, 3(1), 65-90.

Edlin, A., \& Karaca-Mandic, P. (2006). The Accident Externality from Driving. Journal of Political Economy, 114: 65-90.

Gibson, Matthew, and Maria Carnovale. 2015. "The effects of road pricing on driver behaviour and air pollution." Journal of Urban Economics 89: 62-73.

Green, Colin P., John S. Heywood and Maria Navarro. 2016. "Traffic Accidents and the London Congestion Charge,"Journal of Public Economics 113: 11 - 22.

Guerriero, C., Chatzidiakou, L., Cairns, J., \& Mumovic, D. 2016. The economic benefits of reducing the levels of nitrogen dioxide (NO 2) near primary schools: The case of London. Journal of Environmental Management, 181, 615-622.

Hårsman, Bjorn and John M. Quigley. 2010. "Political and Public Acceptability of Congestion Pricing: Ideology and self-interest," Journal of Policy Analysis and Management 29: 854874.

Harvey, Fiona. (2015) "Supreme court orders UK to draw up air pollution cleanup plan," The Guardian, April 29, https://www.theguardian.com/environment/2015/apr/29/supremecourt-orders-uk-to-draw-up-air-pollution-cleanup-plan

Knittel, Christopher R. and Ryan Sandler. 2013. "The Welfare Impact of Indirect Pigouvian Taxation: Evidence from Transportation," NBER Working Paper, No. 18849. 
Knittel, Christopher R., Douglas L. Miller, and Nicholas J. Sanders. 2016 "Caution, drivers!

Children present: Traffic, pollution, and infant health." Review of Economics and Statistics 98: $350-366$.

Leape, Jonathan. 2006. "The London Congestion Charge," Journal of Economic Perspectives 20: $157-76$.

Lim, Stephen M. (et. Al). 2012. "A comparative risk assessment of burden of disease and injury attributable to 67 risk factors and risk factor clusters in 21 regions, 1990-2010: a systematic analysis for the Global Burden of Disease Study 2010," The Lancet 380 (9859): 2224-2260.

Newberry, David M. 1990. "Pricing and Congestion: Economic Principles Relevant to Pricing Roads," Oxford Review of Economic Policy 6: 22- 38.

Platt, S. M. (et al.). 2017. "Gasoline cars produce more carbonaceous particulate matter than modern filter-equipped diesel cars." Scientific Reports 7, Article number: 4926.

Simeonova, E., Currie, J., Nilsson, P., \& Walker, R. (2017). Congestion Pricing, Air Pollution and Children's Health.

Tonne, C., Beevers, S., Armstrong, B., Kelly, F. and Wilkinson, P., 2008. Air pollution and mortality benefits of the London Congestion Charge: spatial and socioeconomic inequalities. Occupational and Environmental Medicine, 65(9), pp.620-627.

Transport for London, 2003. Congestion charging: six months on (London, June).

Transport for London. 2004. "Central London congestion charging, impacts monitoring programme," Second Annual Report London

Transport for London. 2015. "Ultra Low Emission Zone," https://tfl.gov.uk/modes/driving/ultra-low-emission-zone 
Vickrey, William. 1963. "Pricing in Urban and Suburban Transport," American Economic Review 52: 452-65.

Vidal, John. 2013. "Diesel Fumes More Damaging to Health than Petrol Engines," The Guardian, January 27, https://www.theguardian.com/uk/2013/jan/27/diesel-engine-fumesworse-petrol 
Figure 1: The original London Congestion Charge Zone

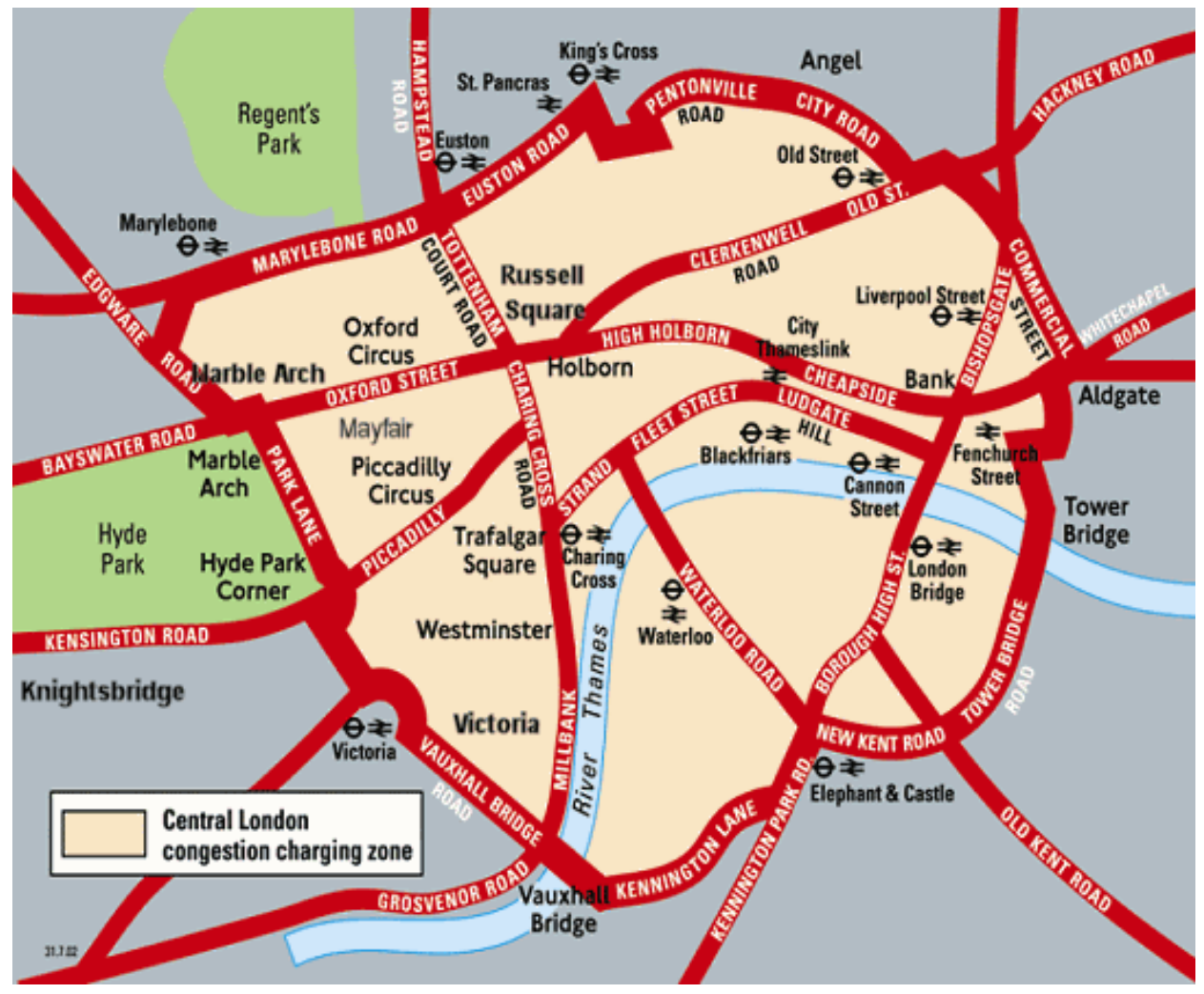

Source: Transport for London (2004 p.8) 
Figure 2: CO, $\mathrm{PM}_{10}$ and $\mathrm{NO}$ (z-scores) Pre and Post CCZ.

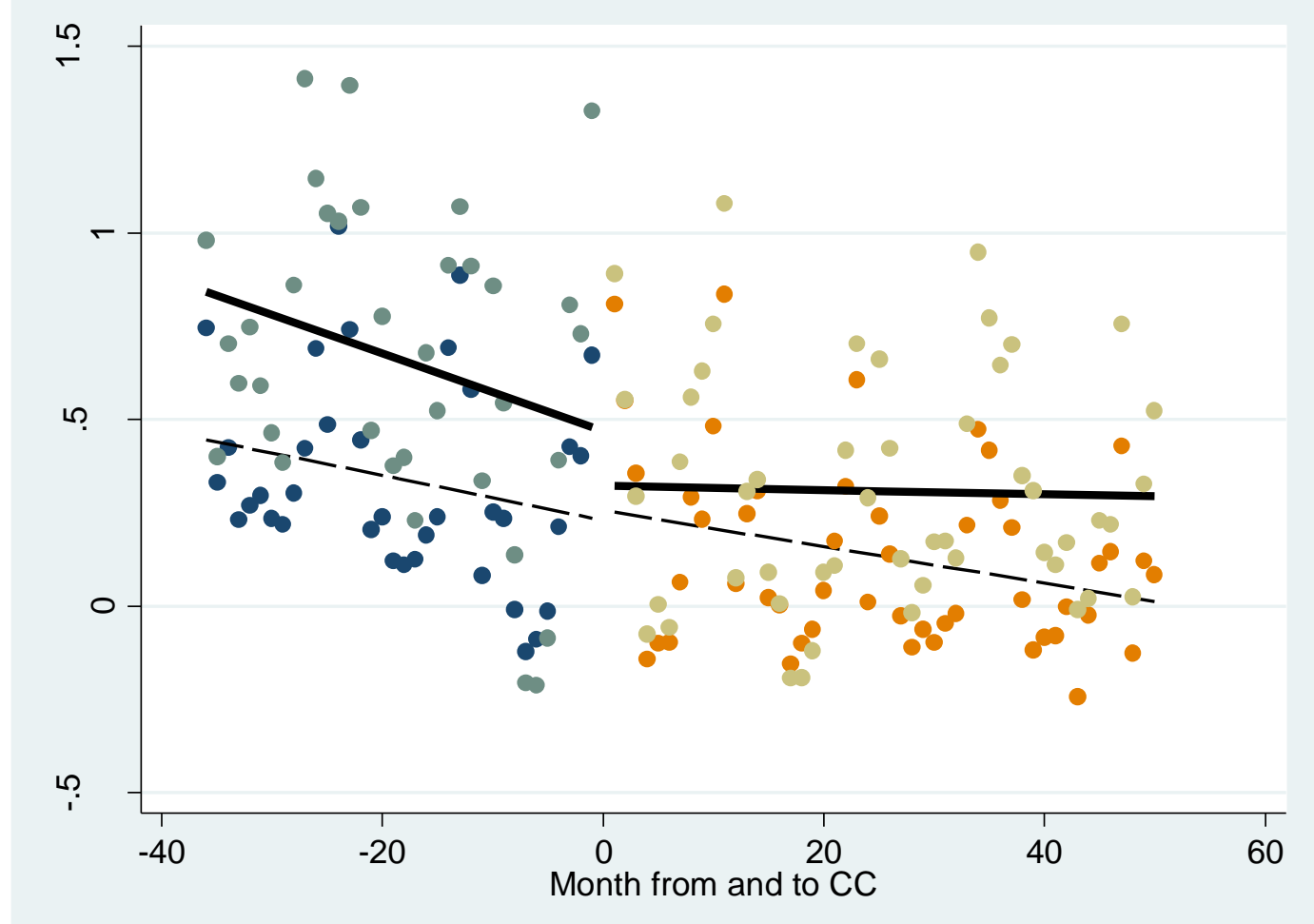

Legend: Solid Line - Congestion Charge Zone

Dashed Line - Comparison Groups 
Figure 3: $\mathrm{NO}_{2}$ Emissions Pre and Post CCZ.

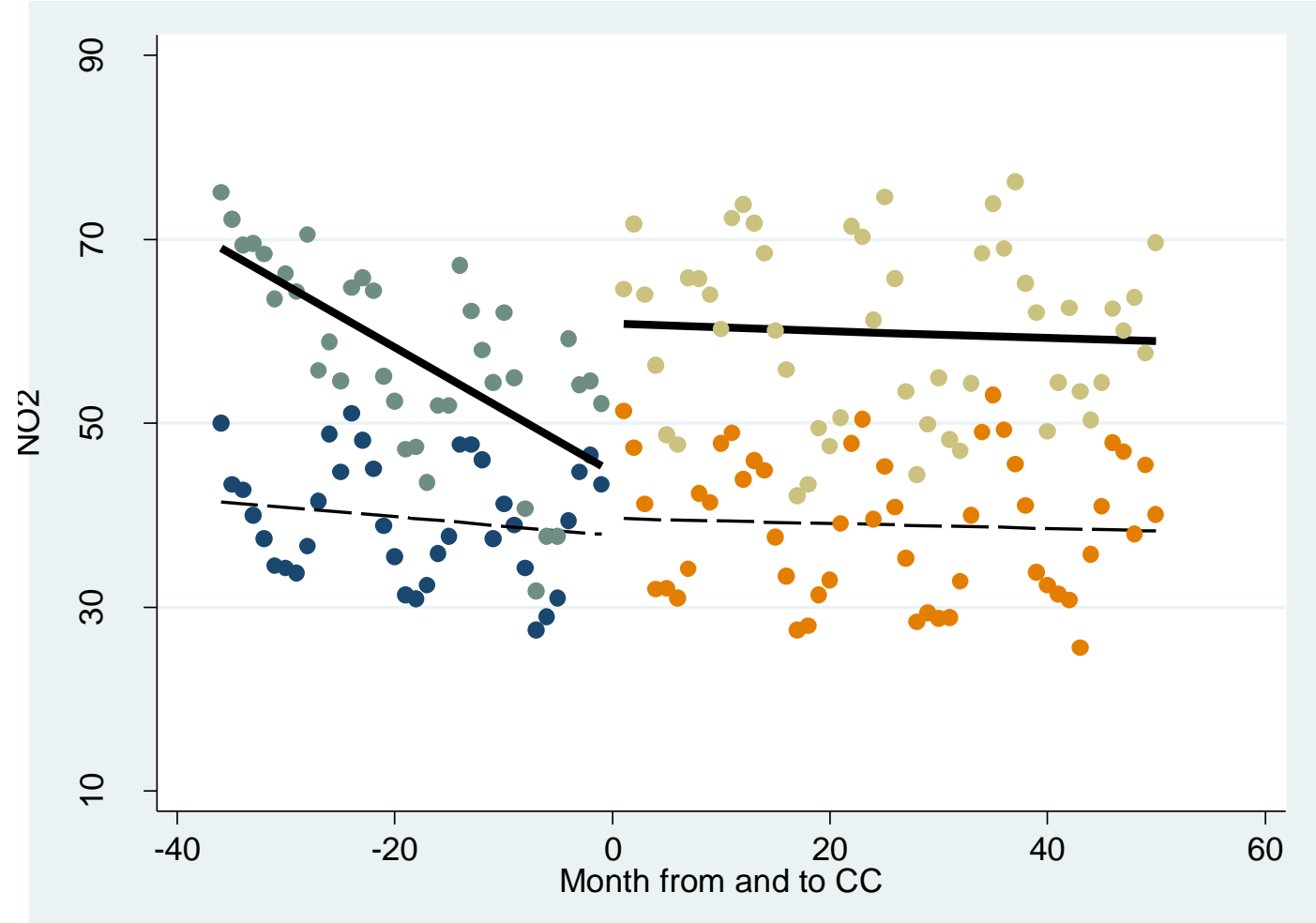

Legend: Solid Line - Congestion Charge Zone

Dashed Line - Comparison Groups 
TABLE 1: The Effect of the Congestion Charge on Hourly Pollution Levels, (CO, $\mathrm{PM}_{10}$, $\mathrm{NO}, \mathrm{NO}_{2}$ )

\begin{tabular}{|c|c|c|c|}
\hline VARIABLES & 2000-05 & 2000-05 & $2000-07$ \\
\hline \multicolumn{4}{|l|}{$\mathrm{CO}$} \\
\hline dd & $\begin{array}{c}-0.068 * * \\
(0.031)\end{array}$ & $\begin{array}{c}-0.034 \\
(0.034)\end{array}$ & $\begin{array}{c}-0.044 \\
(0.030)\end{array}$ \\
\hline p-value (Wild) & 0.054 & 0.382 & 0.186 \\
\hline Observations & 337,080 & 337,080 & 444,430 \\
\hline R-squared & 0.165 & 0.165 & 0.193 \\
\hline \multicolumn{4}{|l|}{ PM10 } \\
\hline dd & $\begin{array}{c}-3.352 * * * \\
(1.073)\end{array}$ & $\begin{array}{c}-6.133 * * * \\
(1.007)\end{array}$ & $\begin{array}{c}-8.566 * * * \\
(0.819)\end{array}$ \\
\hline p-value (Wild) & 0.006 & 0.002 & 0.002 \\
\hline Observations & 316,493 & 316,493 & 421,758 \\
\hline R-squared & 0.075 & 0.076 & 0.081 \\
\hline \multicolumn{4}{|l|}{ NO } \\
\hline dd & $\begin{array}{c}-7.150 * * * \\
(1.539)\end{array}$ & $\begin{array}{l}-0.497 \\
(2.704)\end{array}$ & $\begin{array}{c}-10.142 * * * \\
(2.849)\end{array}$ \\
\hline p-value (Wild) & 0.002 & 0.830 & 0.002 \\
\hline Observations & 342,343 & 342,343 & 457,465 \\
\hline R-squared & 0.132 & 0.133 & 0.138 \\
\hline \multicolumn{4}{|l|}{ NO2 } \\
\hline dd & $\begin{array}{l}2.102 * * \\
(0.827)\end{array}$ & $\begin{array}{c}14.685^{* * * *} \\
(2.395)\end{array}$ & $\begin{array}{c}7.745 * * * \\
(1.473)\end{array}$ \\
\hline p-value (Wild) & 0.044 & 0.000 & 0.000 \\
\hline Observations & 337,149 & 337,149 & 450,310 \\
\hline R-squared & 0.241 & 0.243 & 0.252 \\
\hline $\begin{array}{l}\text { Differential } \\
\text { Trends }\end{array}$ & & $X$ & $X$ \\
\hline
\end{tabular}

Standard Errors clustered at the local authority level in parentheses []. ***,**, * indicate statistical significance at the $1 \%, 5 \%$ and $10 \%$ level, respectively. All models include daily, monitoring station, controls for average temperature, precipitation, average wind spend and average wind direction. 
TABLE 2 The Effect of the Congestion Charge on Hourly Pollution Levels during Charge Time Including Monitoring Station Fixed Effects (CO, $\mathrm{PM}_{10}, \mathrm{NO}, \mathrm{NO}_{2}$ ), 2000-2005/2007

\begin{tabular}{|c|c|c|c|}
\hline \multirow[b]{2}{*}{ VARIABLES } & \multicolumn{3}{|c|}{ Levels } \\
\hline & $2000-05$ & $2000-05$ & 2000-07 \\
\hline \multicolumn{4}{|l|}{$\mathrm{CO}$} \\
\hline \multirow[t]{2}{*}{ dd } & $-0.080 * *$ & -0.038 & -0.044 \\
\hline & $(0.031)$ & $(0.034)$ & $(0.030)$ \\
\hline p-value (Wild) & 0.040 & 0.358 & 0.196 \\
\hline Observations & 337,080 & 337,080 & 444,430 \\
\hline R-squared & 0.171 & 0.172 & 0.199 \\
\hline \multicolumn{4}{|l|}{ PM10 } \\
\hline dd & $\begin{array}{c}-3.701 * * * \\
(1.035)\end{array}$ & $\begin{array}{c}-5.756 * * * \\
(1.068)\end{array}$ & $\begin{array}{c}-8.568 * * * \\
(0.805)\end{array}$ \\
\hline p-value (Wild) & 0.002 & 0.002 & 0.002 \\
\hline Observations & 316,493 & 316,493 & 421,758 \\
\hline R-squared & 0.073 & 0.073 & 0.078 \\
\hline \multicolumn{4}{|l|}{ NO } \\
\hline dd & $\begin{array}{c}-8.015^{* * *} * \\
(1.905) \\
0.002\end{array}$ & $\begin{array}{c}-4.464 * \\
(2.574) \\
0.018\end{array}$ & $\begin{array}{c}-11.367 * * * \\
(2.576) \\
0.006\end{array}$ \\
\hline Observations & 342,343 & 342,343 & 457,465 \\
\hline R-squared & 0.146 & 0.146 & 0.148 \\
\hline \multicolumn{4}{|l|}{ NO2 } \\
\hline dd & $\begin{array}{c}1.755 * * \\
(0.670) \\
0.494\end{array}$ & $\begin{array}{c}9.861 * * * \\
(2.313) \\
0.000\end{array}$ & $\begin{array}{c}4.738 * * * \\
(1.587) \\
0.004\end{array}$ \\
\hline Observations & 337,149 & 337,149 & 450,310 \\
\hline R-squared & 0.203 & 0.204 & 0.209 \\
\hline $\begin{array}{l}\text { Differential } \\
\text { Trends }\end{array}$ & & $X$ & $X$ \\
\hline $\begin{array}{l}\text { Monitoring } \\
\text { Station FE }\end{array}$ & $X$ & $X$ & $X$ \\
\hline
\end{tabular}

Standard Errors clustered at the local authority level in parentheses []. ***, **, * indicate statistical significance at the $1 \%, 5 \%$ and $10 \%$ level, respectively. All models include daily, monitoring station, controls for average temperature, precipitation, average wind spend and average wind direction. 
TABLE 3 The Effect of the Congestion Charge on Hourly Pollution (Logs) during Charge Time Including Monitoring Station Fixed Effects (CO, PM ${ }_{10}, \mathrm{NO}, \mathrm{NO}_{2}$ ), 2000-2005/2007

\begin{tabular}{|c|c|c|c|}
\hline \multirow[b]{2}{*}{ VARIABLES } & \multicolumn{3}{|c|}{ Logs Pollution } \\
\hline & 2000-05 & $2000-05$ & $2000-07$ \\
\hline \multicolumn{4}{|l|}{$\mathrm{CO}$} \\
\hline \multirow[t]{2}{*}{ dd } & $-0.131 *$ & -0.119 & -0.062 \\
\hline & $(0.069)$ & $(0.108)$ & $(0.076)$ \\
\hline p-value (Wild) & 0.063 & 0.416 & 0.426 \\
\hline Observations & 333,677 & 333,677 & 441,027 \\
\hline R-squared & 0.185 & 0.185 & 0.230 \\
\hline \multicolumn{4}{|l|}{ PM10 } \\
\hline \multirow[t]{2}{*}{ dd } & $-0.102 * * *$ & $-0.092 * *$ & $-0.246 * * *$ \\
\hline & $(0.028)$ & $(0.033)$ & $(0.028)$ \\
\hline p-value (Wild) & 0.006 & 0.012 & 0.002 \\
\hline Observations & 315,926 & 315,926 & 420,957 \\
\hline R-squared & 0.103 & 0.103 & 0.106 \\
\hline \multicolumn{4}{|l|}{ NO } \\
\hline \multirow[t]{2}{*}{ dd } & $-0.235 * * *$ & -0.109 & $-0.301 * * *$ \\
\hline & $(0.066)$ & $(0.082)$ & $(0.070)$ \\
\hline p-value (Wild) & 0.074 & 0.358 & 0.012 \\
\hline Observations & 340,010 & 340,010 & 454,371 \\
\hline R-squared & 0.183 & 0.183 & 0.187 \\
\hline \multicolumn{4}{|l|}{ NO2 } \\
\hline \multirow[t]{2}{*}{ dd } & $0.033 *$ & $0.199 * * *$ & $0.092 * *$ \\
\hline & $(0.017)$ & $(0.034)$ & $(0.034)$ \\
\hline p-value (Wild) & 0.054 & 0.000 & 0.006 \\
\hline Observations & 337,131 & 337,131 & 450,288 \\
\hline R-squared & 0.187 & 0.188 & 0.193 \\
\hline $\begin{array}{l}\text { Differential } \\
\text { Trends }\end{array}$ & & $X$ & $X$ \\
\hline
\end{tabular}

Standard Errors clustered at the local authority level in parentheses []. ***, **, * indicate statistical significance at the $1 \%, 5 \%$ and $10 \%$ level, respectively. All models include daily, monitoring station, controls for average temperature, precipitation, average wind spend and average wind direction. 
TABLE 4. The Effect of the Congestion Charge on the Rate of Annual Pollution during Charge Time 2000-2007. Charged Miles (Millions)

\begin{tabular}{|c|c|c|c|c|}
\hline & $\mathrm{CO}$ & PM10 & NO & $\mathrm{NO} 2$ \\
\hline \multirow[t]{3}{*}{ DD } & -0.030 & $-12.855^{* * *}$ & $-10.013 * * *$ & $20.787 * * *$ \\
\hline & $(0.070)$ & (2.101) & (3.292) & (1.780) \\
\hline & 0.660 & 0.002 & 0.002 & 0.000 \\
\hline \multirow[t]{2}{*}{ Policy } & 0.089 & $4.103^{*}$ & 2.108 & $4.209 * *$ \\
\hline & $(0.070)$ & (2.101) & $(3.292)$ & (1.780) \\
\hline \multirow[t]{2}{*}{ Trend } & $-0.124 * * *$ & $-1.875 * * *$ & $-3.880 * * *$ & $-2.628 * * *$ \\
\hline & $(0.025)$ & $(0.527)$ & $(0.694)$ & $(0.532)$ \\
\hline \multirow[t]{2}{*}{ Trend*Policy } & 0.033 & $3.851 * * *$ & $4.633 * * *$ & 0.276 \\
\hline & $(0.025)$ & $(0.527)$ & $(0.694)$ & $(0.532)$ \\
\hline $\begin{array}{l}\text { Monitoring } \\
\text { Station FE }\end{array}$ & $X$ & $X$ & $X$ & $X$ \\
\hline Observations & 152 & 146 & 154 & 154 \\
\hline r2 & 0.521 & 0.112 & 0.287 & 0.220 \\
\hline
\end{tabular}

Standard Errors clustered at the local authority level in parentheses []. ***,**, * indicate statistical significance at the $1 \%, 5 \%$ and $10 \%$ level, respectively. All models include annual, monitoring station, controls for average temperature, precipitation, average wind spend and average wind direction. 
TABLE 5: The Congestion Charge and Annual Traffic Flows, 2000-2005 (in millions)

\begin{tabular}{|c|c|c|c|c|c|c|c|}
\hline & Total & Cars/Taxis & Light Goods & $\begin{array}{l}\text { Heavy } \\
\text { Goods }\end{array}$ & Bicycles & $\begin{array}{l}\text { Motor } \\
\text { Cycles }\end{array}$ & Buses \\
\hline \multirow[t]{2}{*}{ DD } & $-7.587^{*}$ & $-14.065^{* * *}$ & $1.468 * * *$ & $-3.106^{* * *}$ & $1.814 * * *$ & $4.852 * * *$ & $2.679 * * *$ \\
\hline & (3.928) & $(3.475)$ & $(0.000)$ & $(0.490)$ & $(0.110)$ & $(0.125)$ & $(0.213)$ \\
\hline \multirow[t]{2}{*}{ POLICY } & 2.581 & -0.109 & $0.000 * * *$ & $1.282 * *$ & $0.634 * * *$ & $0.450 * * *$ & $-0.866 * * *$ \\
\hline & (3.928) & $(3.475)$ & $(0.000)$ & $(0.490)$ & $(0.110)$ & $(0.125)$ & $(0.213)$ \\
\hline \multirow[t]{2}{*}{$\mathrm{CCZ}$} & 11.950 & -46.329 & $79.565^{* * * *}$ & -14.033 & $14.604 * * *$ & $37.100 * * *$ & $12.333 * * *$ \\
\hline & (116.328) & (92.027) & $(0.000)$ & $(9.870)$ & $(0.350)$ & $(0.642)$ & (1.617) \\
\hline \multirow[t]{2}{*}{ Trend } & $7.016^{* * *}$ & $5.367 * * *$ & $-0.000 * * *$ & 0.106 & $-0.209 * * *$ & $-0.101^{*}$ & $-0.121 * *$ \\
\hline & (2.165) & (1.583) & $(0.000)$ & $(0.129)$ & $(0.028)$ & $(0.052)$ & $(0.043)$ \\
\hline \multirow[t]{2}{*}{ Trend * Policy } & $-19.999 * * *$ & $-22.573 * * *$ & $-0.080 * * *$ & $-0.839 * * *$ & $3.320 * * *$ & $0.893 * * *$ & $1.228 * * *$ \\
\hline & $(2.165)$ & (1.583) & $(0.000)$ & $(0.129)$ & $(0.028)$ & $(0.052)$ & $(0.043)$ \\
\hline \multirow[t]{2}{*}{ Constant } & $687.415^{* * *}$ & $559.445^{* * *}$ & $0.000 * * *$ & $39.172 * * *$ & $2.864 * * *$ & $5.299 * * *$ & $9.483 * * *$ \\
\hline & (116.328) & (92.027) & $(0.000)$ & $(9.870)$ & $(0.350)$ & $(0.642)$ & (1.617) \\
\hline Observations & 132 & 132 & 132 & 132 & 132 & 132 & 132 \\
\hline
\end{tabular}

$* * *, * *, *$ indicate statistical significance at the $1 \%, 5 \%$ and $10 \%$ level, respectively. 
TABLE 6: Synthetic Control Estimates of the CCZ effect on Pollution, 2000-2007

\begin{tabular}{|c|c|c|c|}
\hline VARIABLES & 2000-05 & 2000-05 & 2000-07 \\
\hline \multicolumn{4}{|l|}{$\mathrm{CO}$} \\
\hline dd & $\begin{array}{c}-0.019 \\
(0.061)\end{array}$ & $\begin{array}{c}-0.175 \\
(0.120)\end{array}$ & $\begin{array}{c}-0.112 \\
(0.091)\end{array}$ \\
\hline Observations & 144 & 144 & 192 \\
\hline R-squared & 0.317 & 0.328 & 0.459 \\
\hline \multicolumn{4}{|l|}{ PM10 } \\
\hline dd & $\begin{array}{c}-0.513 \\
(1.834)\end{array}$ & $\begin{array}{l}-4.433 \\
(3.645)\end{array}$ & $\begin{array}{l}-5.182^{*} \\
(2.944)\end{array}$ \\
\hline Observations & 144 & 144 & 192 \\
\hline R-squared & 0.232 & 0.241 & 0.292 \\
\hline \multicolumn{4}{|l|}{ NO } \\
\hline dd & $\begin{array}{c}-1.977 \\
(5.198)\end{array}$ & $\begin{array}{c}-1.683 \\
(10.389)\end{array}$ & $\begin{array}{l}-6.539 \\
(8.470)\end{array}$ \\
\hline Observations & 144 & 144 & 192 \\
\hline R-squared & 0.080 & 0.080 & 0.099 \\
\hline \multicolumn{4}{|l|}{ NO2 } \\
\hline dd & $\begin{array}{c}6.261 * * \\
(2.980)\end{array}$ & $\begin{array}{c}21.143 * * * \\
(5.773)\end{array}$ & $\begin{array}{c}14.205 * * * \\
(5.206)\end{array}$ \\
\hline Observations & 144 & 144 & 192 \\
\hline R-squared & 0.309 & 0.351 & 0.328 \\
\hline $\begin{array}{l}\text { Differential } \\
\text { Trends }\end{array}$ & & $X$ & $X$ \\
\hline
\end{tabular}

Standard Errors clustered at the local authority level in parentheses ().***,**,* indicate statistical significance at the $1 \%, 5 \%$ and $10 \%$ level, respectively. 
TABLE 7: Alternative Inference as per Conley and Taber (2011)

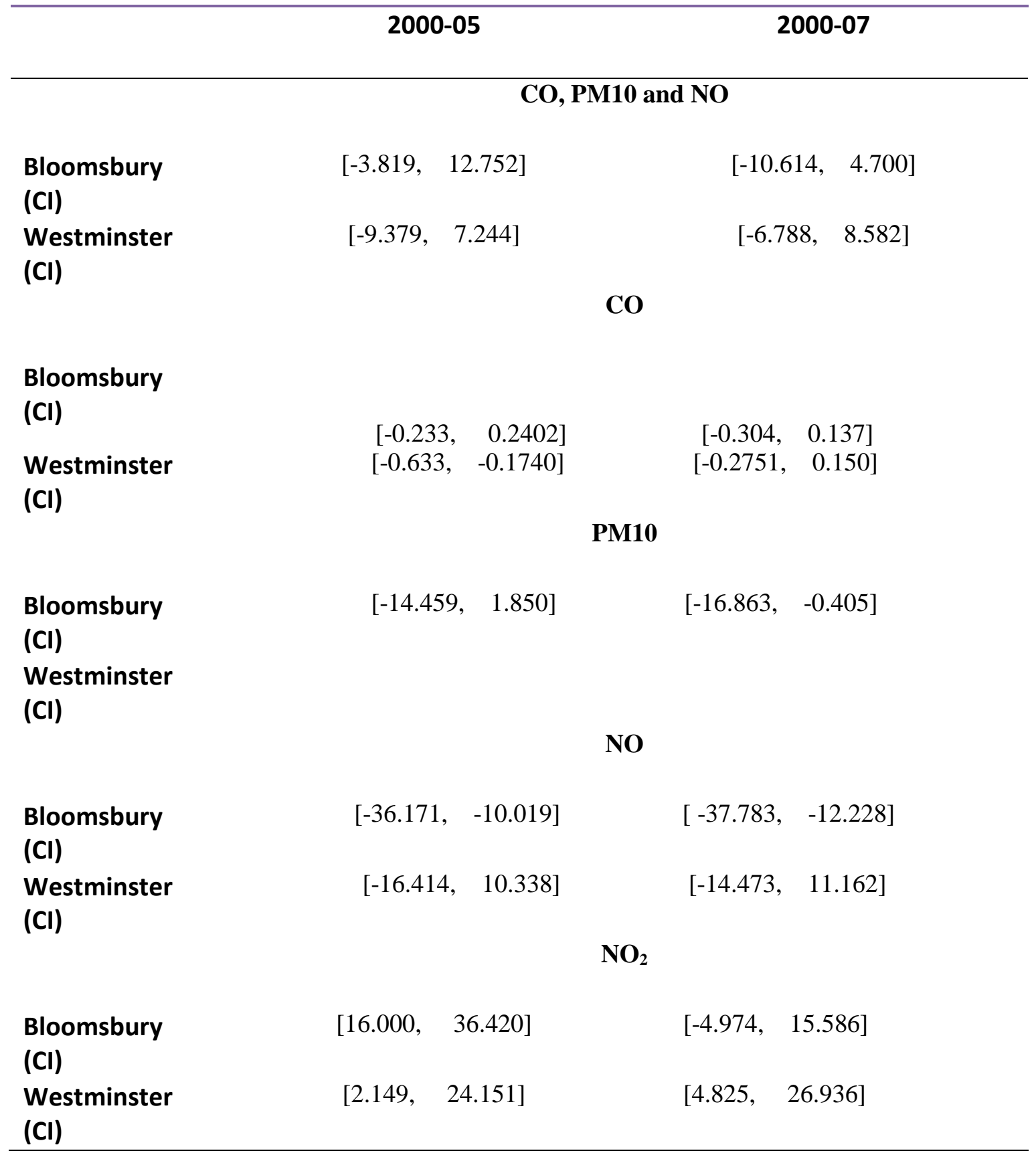

The bounds presented are those for the $95 \%$ confidence interval. 
APPENDIX TABLE A1: Descriptive Statistics

\begin{tabular}{lccccc}
\hline & & & Standard & \\
Variables & Observations & Mean & Dev & Min & Max \\
\hline CO & 444,430 & 0.435 & 0.358 & 0 & 15.1 \\
PM10 & 421,758 & 27.3325 & 19.140 & -5 & 1097 \\
NO & 457,465 & 30.250 & 44.433 & 0 & 1454 \\
NO2 & 450,310 & 40.526 & 20.451 & 0 & 397 \\
Av Temperature & 450,310 & 10.050 & 4.983 & -7.05 & 25.9 \\
Av Precipitation & 450,310 & 2.549 & 5.473 & 0 & 107.2 \\
Mean Wind direction & 450,310 & 202.135 & 70.742 & 0 & 608.667 \\
Mean Wind speed & 450,310 & 8.201 & 4.360 & 0 & 45.125 \\
\hline & & & & & \\
\hline & & & & & \\
\hline CO rate Total Miles & 152 & 0.839 & 0.536 & 0.089 & 2.642 \\
CO rate Miles Charged & 152 & 0.975 & 0.624 & 0.105 & 3.043 \\
PM10 rate Total Miles & 146 & 49.478 & 23.905 & 9.518 & 129.393 \\
PM10 rate Miles Charged & 146 & 57.571 & 28.319 & 11.119 & 153.827 \\
NO rate Total Miles & 154 & 53.729 & 28.255 & 11.251 & 159.087 \\
NO rate Miles Charged & 154 & 62.482 & 33.051 & 12.894 & 183.225 \\
NO2 rate Total Miles & 154 & 73.033 & 32.256 & 14.729 & 174.414 \\
NO2 rate Miles Charged & 154 & 85.018 & 38.203 & 17.206 & 207.350 \\
Total Miles (in millions) & 154 & 0.738 & 0.556 & 0.263 & 2.711 \\
Miles in Charge period & 154 & 0.637 & 0.479 & 0.220 & 2.298
\end{tabular}

\begin{tabular}{lcccc}
\hline & \multicolumn{2}{c}{ Pre-Congestion charge } & \multicolumn{2}{c}{$\begin{array}{c}\text { CCZ pre-congestion charge } \\
\text { implementation }\end{array}$} \\
& Mean & Std. Dev. & Mean & Std. Dev. \\
\hline CO & 0.554 & 0.430 & 0.618 & 0.402 \\
PM10 & 28.169 & 21.250 & 34.890 & 20.449 \\
NO & 34.027 & 49.076 & 44.214 & 44.564 \\
NO2 & 41.106 & 19.510 & 56.700 & 20.534 \\
\hline
\end{tabular}

